\title{
Representações sobre consumo alimentar e suas implicações em inquéritos alimentares: estudo qualitativo em sujeitos submetidos à prescrição dietética ${ }^{1}$
}

\section{Representations on food intake and its implications in nutritional investigations: qualitative study with subjects submitted to dietary prescriptions}

Rosa Wanda Diez GARCIA²

RE S U M O

\section{Objetivo}

A presentar e discutir o caráter flexível que emergiu nos relatos sobre consumo alimentar em estudo qualitativo para avaliar práticas alimentares de pessoas submetidas a tratamento dietético por serem hipertensas e 0 impacto da preocupação com a saúde nestas. Os relatos de consumo alimentar foram analisados como representações sociais e se discutiu as implicações destas em inquéritos dietéticos.

\section{Métodos}

Em visita domiciliar foram entrevistados 30 hipertensos, sendo 15 de baixa renda e 15 de classe média. Para obtenção de informações sobre consumo alimentar foram aplicados os métodos recordatório alimentar de 24 horas, associado à história dietética e a um questionário de freqüência alimentar, no contexto de uma entrevista em profundidade semi-estruturada. As entrevistas foram gravadas, transcritas e analisadas em seu conteúdo.

\section{Resultados}

Situadas entre o discurso e as práticas, as representações expressaram flutuações e contradições sobre o consumo alimentar. Tais representações foram agrupadas em categorias apresentadas como: irregularidade da presença do alimento e das compras; modo de consumo conforme o tipo de alimento; variação do número de comensais; indução das respostas provocada pela busca de informações precisas por parte do entrevistador; falta de memória do entrevistado; imprecisão e contrariedade de relatos sobre consumo alimentar; uso de

\footnotetext{
${ }^{1}$ Financiado pelo CNPq.

2 Faculdade de Nutrição, Centro de Ciências da Vida, PUC-Campinas. Av. John Boyd Dunlop, s/n, 13059-900, Prédio Administrativo. Campinas, SP, Brasil. E-mail: rwdg@dglnet.com.br
} 
noções quantitativas cujos valores de referência são particulares ao sujeito e presença de terceiros testemunhando a entrevista. A estratégia metodológica utilizada permitiu observar que há menos precisão nas informações sobre consumo alimentar do que o esperado, por serem estas representações sociais, ou seja, construções mentais da realidade. Os resultados também sugerem que a abordagem da alimentação de sujeitos submetidos à prescrição dietética por meio de inquéritos alimentares pode ser insuficiente para conhecer suas práticas alimentares.

Termos de indexação: consumo de alimentos, inquéritos nutricionais, representação social, hipertensão, dieta.

\section{A B S T R A C T}

\section{Objective}

The objective of this qualitative study was to present and discuss the flexible characteristics emerging from reports on food intake of patients submitted to dietary treatment for hypertension control and the impact of anxiety on their health. Food intake reports were analyzed as social representations and their implications in nutritional investigations were discussed.

\section{Methods}

Thirty hypertensive subjects were interviewed by means of home visits; 15 were low-income and 15 were middle-class individuals. The 24-hour diet recall method was used to obtain information on food intake, in association with diet history and a questionnaire on meal frequency, in the context of semi-structured indepth interviews which were taped, transcribed and had their content analyzed.

\section{Results}

Social representations situated between theory and practice expressed fluctuations and contradictions regarding food intake. Such representations were grouped in categories such as: irregularity in food ingestion and food purchasing; intake method in accordance with the type of food served; oscillation in the number of people eating together; answers induced by the interviewer in search of accurate answers; lack of memory of the interview ed; imprecision and divergent reports on food intake; use of quantitative parameters whose reference values are sensitive to the subject and the presence of third parties witnessing the interview. The methodological strategy employed allowed the observation that there is less precision in the information on food intake than expected, as a result of its being composed of social representations, that is to say, mental constructions of reality. The results also suggest that the food inquiry approach for subjects submitted to dietary prescription may be insufficient to investigate their eating habits.

Index terms: food intake, food inquiry, social representation, hypertension, diet.

\section{N T R O D U ÇÃ O}

Conhecer exatamente a ingestão alimentar de grupos ou mesmo de indivíduos é sempre uma tarefa complexa pelas práticas alimentares estarem mergulhadas nas dimensões simbólicas da vida social, envolvidas nos mais diversos significados, desde o âmbito cultural até as experiências pessoais, conferindo a elas menos objetividade do que se espera ao abordá-las por meio de métodos de investigação sobre consumo alimentar. A possibilidade de existência daquilo que se intitula viés na coleta de informações, pode também ser entendido como uma decorrência inerente a uma prática menos objetiva do que o desejado pelas investigações sobre 0 assunto. 
Em estudo com trabalhadores do centro da cidade de São Paulo foram investigadas representações sociais so bre alimentação e saúde, no qual foi constatado que em diferentes circunstâncias, por motivos diversos, afloram representações de modo variável e seletivo, adequando-se a elas, delineando diferentes perfis de representações e práticas que ocorrem no âmbito alimentar. Sendo as representações sociais construções mentais da realidade ${ }^{2,3}$, segundo o alvo de uma dada circunstância, alguns constituintes das representações são enfocados e outros desfocados. As representações sobre as práticas alimentares vão manifestar conflitivamente as oscilações do comportamento alimentar ora construídas pela preocupação com a saúde, ora por outros valores. Esta estrutura móvel observada na análise das representações sociais suscita reflexões sobre a estabilidade das informações sobre consumo alimentar.

Keane \& Willetts ${ }^{4}$ em estudo utilizando métodos qualitativos e quantitativos sobre concepções de alimentação saudável realizado na Região Sudeste de Londres apresentam os comentários e o relato de um registro diário de sete dias no qual o sujeito da pesquisa se surpreende com a variação e irregularidade do próprio consumo alimentar, denunciando a fragilidade da consciência sobre esta prática.

No modo de vida urbano, sobretudo nas grandes cidades, a alimentação tem se deslocado do ambiente doméstico, condição esta que dificulta abordar o consumo alimentar por meio dos métodos de inquérito alimentar devido à diversidade de alimentos e preparações que podem compor um prato, dificultando a descrição do consumido; a variedade de utensílios e itens alimentares prejudica as condições para se registrar mentalmente as porções ingeridas; 0 desconhecimento dos ingredientes e do modo de preparo dos pratos, entre outras. Pessoas que comem na rua podem, no decorrer do mês, almoçar em diferentes lugares, optar por lanches ou salgadinhos ou mesmo trazer comida de casa, situações que ampliam consideravelmente a instabilidade da presença de alimentos de rotina.

A história dietética, por exemplo, por ser um método que busca registrar a alimentação habitual, pressupõe alguma rotina alimentar a qual pode estar estruturada - refeição em horários estabelecidos e com alimentos e preparações estáveis determinados culturalmente - ou desestruturada - sem horários fixos e fazendo uso de alimentos variáveis sem seguir qualquer regra alimentar. Nas situações em que predomina a alimentação mais desestruturada, a qualificação e quantificação do consumo tendem a ser mais vulneráveis à imprecisão, uma vez que aumenta a diversidade de itens alimentares e reduz sua previsibilidade. Refeições formais podem ser mais facilmente memorizadas do que o consumido junto a outras atividades e nos intervalos das grandes refeições. Aquilo que se come mais por seu caráter de lazer, de sociabilidade, do que propriamente para alimentar, pode ter outro registro na memória. É difícil alguém se lembrar de quantos petiscos comeu numa festa de casamento, ou tomando cerveja com os amigos, enfim, há ocasiões onde a prática alimentar está inserida em outros contextos, que podem torná- la uma decorrência destes, refletindo na qualidade de sua percepção.

Witschi ${ }^{5}$ menciona possíveis fontes de erros que podem distorcer as informações sobre ingestão alimentar: a percepção do que se come; a memória do entrevistado; efeitos decorrentes da idade, sexo e ambiente da entrevista; a própria coleta de dados pode afetar as informações de ingestão; a variação alimentar diária e a sazonalidade, os dias em que são realizadas as entrevistas podem ser mais ou menos representativos que outros; a habilidade do entrevistador em obter informações e a disposição em colaborar com a investigação.

Nos métodos recordatório alimentar de 24 horas e na história dietética que dependem respectivamente do relato do que foi consumido ou do que é habitualmente ingerido, a memória e a percepção são condições para garantir a 
qualidade da informação. Mas, a memória pode produzir distorções consideráveis, tanto de forma consciente como inconsciente. A memória seletiva, leva o sujeito a lembrar-se dos alimentos mais aceitos socialmente, ou a enfocar o consumo desejável e pode, com isso, subnotificar grandes quantidades ingeridas ou supernotificar as pequenas quantidades ${ }^{6}$. Uma tendência de subvalorização de ingestão alimentar utilizando o método recordatório alimentar de 24 horas é observada por diversos autores através de estudos comparativos já bem conhecidos ${ }^{7-9}$. As dificuldades na obtenção de informações mais precisas têm levado pesquisadores a recomendarem biomarcadores para diagnóstico de consumo de micronutrientes ${ }^{10-11}$.

A fidelidade da percepção do que se come também é um requisito importante para obter dados confiáveis. Uma pessoa ao referir o que come, pode manifestar uma idealização de sua alimentação. Em algumas situações, como na obesidade, por exemplo, o registro da ingestão alimentar tende a ser subestimado ${ }^{12}$. 0 próprio fato de sentir-se observado produz mudanças na dieta, seja para demonstrar uma dieta idealizada, seja para impressionar o investigador. A magnitude e a direção do efeito provocado por um observador vão depender das normas culturais locais, da expectativa do entrevistado com relação àquela investigação, da interação entre investigador e o sujeito entrevistado, entre outros ${ }^{13}$.

As condições econômicas e socioculturais influenciam as representações sobre alimentação, uma vez que esta pode expressar tal condição, podendo tender a superestimação para minimizar a dimensão da pobreza ou subestimando o consumido segundo a expectativa do entrevistado com relação à pesquisa.

Carrasco i Pons ${ }^{14}$ ao se ocupar em construir um arcabouço teórico para os sistemas alimentares, sugere três proposições, dentre as quais uma trata da existência de uma distância entre a visão que os indivíduos manifestam de suas práticas e as práticas propriamente ditas. Havendo modelos de relações sociais em que estas práticas se fundamentam, esta distância será orientada por estes. Sendo assim, numa sociedade culturalmente homogênea, o comportamento esperado seria o de adaptação ao modelo alimentar dominante, segundo as possibilidades econômicas do grupo e, em uma sociedade culturalmente heterogênea, os diferentes graus de aculturação - fenômeno resultante do contato entre grupos de culturas diferentes que, após convivência direta e contínua, provoca mudanças na cultura de origem de um ou de ambos os grupos $^{15}$ - apresentariam sistemas dicotômicos e duais. Observa-se esta proposição nas pressões econômicas e culturais que podem levar à substituição alimentar, à xenofobia ou ao consumo alimentar oculto.

Um modelo de consumo alimentar mais hegemônico pode estar sendo manifestado numa situação de inquérito alimentar, não por falta de sinceridade, mas pelo próprio descompasso entre o que a pessoa acha que come e o que propriamente come, de modo a expressar um sentimento de pertencer ao padrão alimentar idealizado socialmente. Um exemplo disto ocorre quando é exacerbado o consumo de alimentos mais aceitos como de boa qualidade e subnotificado àqueles tidos como ruins (fast food, snacks, bebida alcoólica, cigarro) ${ }^{16}$.

Com o intuito de avaliar práticas alimentares de pessoas submetidas a tratamento dietético e o impacto da preocupação com a saúde nestas, foi realizado inquérito alimentar no contexto de uma pesquisa de abordagem qualitativa, em sujeitos pertencentes a condições socioeconômicas distintas, que foram submetidos a prescrição dietética por serem hipertensos. Os procedimentos realizados para aplicação deste tipo de inquérito nos permitiu observar algumas características de relato que manifestam um caráter oscilante, flexível e, às vezes, contraditório, das representações das práticas alimentares. Dado o interesse desta característica das práticas alimentares para estudos que avaliam o consumo alimentar, 0 objetivo deste trabalho foi apresentar e discutir como tais representações podem ter implicações em inquéritos dietéticos. 


\section{CASUÍSTICA E MÉTODOS}

Foram entrevistados 30 adultos com diagnóstico de hipertensão arterial, agrupados da seguinte maneira: 15 indivíduos que faziam uso do serviço público de saúde na região leste da cidade de Campinas, região com população de baixa renda (grupo 1 - indicado nos relatos com numeração de 1 a 15) e outros 15 eram tratados em serviços de saúde privados (grupo 2 - indicados nos relatos com numeração de 100 a 115). A intenção deste agrupamento de entrevistados era justamente a de ter dois grupos de sujeitos com indicadores de pertinência a diferentes estratos sociais.

No grupo 1 a renda per capita variou entre 0,5 e 4,0 salários mínimos, sendo que 8 sujeitos ganhavam entre 0,5 e 1,0 salário mínimo; a escolaridade dos entrevistados e chefes de família variou entre 0 analfabetismo e o segundo grau incompleto e completo, respectivamente; a idade média foi de $61 \pm 8$ anos, variando de 48 a 75 anos; 5 dos entrevistados eram aposentados, 2 pensionistas, 5 eram donas de casa e portanto não tinham vínculo empregatício e apenas 3 estavam no mercado de trabalho, sendo que um deles encontrava-se desempregado na ocasião da entrevista. No grupo 2 a renda per capita variou entre 3,5 a 13 salários mínimos, a escolaridade mínima foi primeiro grau incompleto (2 sujeitos) e a máxima foi formação de nível superior ( 5 sujeitos); a idade média foi de $55 \pm 9$ anos, variando de 42 a 70. Seis estavam empregados; 3 eram autônomos; 1 estava aposentado e 5 eram donas de casa. Além destes últimos, foram entrevistados funcionários públicos, professores (universitário e de $2^{\circ}$ grau), comerciante, vendedor, administrador de empresa e aeroviário.

A aplicação do inquérito alimentar se deu no contexto de uma entrevista em profundidade, semi-estruturada, cujo objetivo era conhecer diferentes aspectos de sua experiência no convivio com a hipertensão. As entrevistas foram realizadas no domicílio do entrevistado, gravadas e transcritas.
O entrevistado desconhecia a identidade profissional do entrevistador e seu interesse específico por questões alimentares. A explicação prévia sobre a pesquisa continha um comentário afirmando ser muito difícil seguir as recomendações médicas por condições impostas pelo cotidiano. Assim sendo, o objetivo da pesquisa era conhecer como estas dificuldades se apresentavam no dia-a-dia das pessoas para evitar que o entrevistado pudesse sentir-se julgado.

A entrevista semi-estruturada, pela sua forma de condução, tem as características do que Queiroz ${ }^{17}$ denominou depoimento pessoal. Este tipo de entrevista facilita a análise de testemunhos em relação a variáveis pré-determinadas. Permite introduzir elementos e aprofundar outros evitando a dispersão mais ou menos caótica da entrevista aberta não estruturada.

As informações sobre consumo alimentar foram obtidas através do método recordatório alimentar de 24 horas associado a informações sobre dieta habitual (história dietética) e um questionário de freqüência alimentar, com o objetivo de avaliar o consumo da dieta habitual dos dois grupos estudados, o qual deu origem a análise dos relatos dos inquéritos alimentares. 0 diferencial no uso destes tipos de inquéritos foi conduzir o mínimo possível às questões sobre alimentação, permitindo idas e vindas no assunto e encaminhar a entrevista de modo a não antecipar informações sobre as quantidades e a periodicidade de consumo, não definindo de antemão a freqüência e unidade de consumo, com o objetivo de conhecer como é feita esta organização pelo próprio sujeito, buscando assim uma forma menos indutiva de adquirir informações. Quando a informação não era fornecida se aguardava, ao longo da conversa, ocasião para esclarecê-la evitando pressionar o entrevistado para fornecer informações precisas. Não foi realizado nenhum tipo de anotação durante a entrevista, apenas o registro por gravação.

Como o método recordatório de 24 horas foi aplicado apenas por um dia (o recomendável 
é repeti-lo ao menos por 3 dias), o que reduz sua representatividade para caracterizar a dieta habitual, a informação sobre a alimentação do dia-a-dia e dos fins de semana foi colhida como estratégia metodológica para conferir se as informações eram representativas do cotidiano alimentar dos entrevistados. Para a realização do recordatório alimentar de 24 horas foi utilizado um álbum fotográfico ${ }^{18} \mathrm{com}$ porções de alimentos, que foi colocado à disposição do entrevistado para ele reconhecer as porções do que ele havia comido.

O questionário de freqüência foi construído em 3 partes que corresponderam a categorias de alimentos que demandaram diferentes estratégias para obtenção de informação:

1. A primeira categoria foi de alimentos cuja abordagem de consumo era através da disponibilidade per capita como: óleo, sal, temperos prontos, açúcar e margarina (e/ou manteiga), - considerados "invisíveis" por serem utilizados em preparações ou, como é o caso da margarina e do açúcar, por serem sempre consumidos associados a outro alimento - , 0 arroz e o feijão pela facilidade de quantificá-los pelas compras periódicas. A pergunta que caracterizou esta categoria de alimentos foi a quantidade comprada pelo período em que o entrevistado costumava fazer suas compras.

2. 0 segundo grupo de alimentos, formado pelo pão, leite, frutas, vegetais e carnes, frango ou peixe teve seu consumo checado pela freqüência de consumo diário individual habitual. Foi quantificada a unidade consumida de pão e de fruta; a quantidade em mililitros de leite e a periodicidade de consumo de vegetais e carnes, frango ou peixe, sem quantificação. A forma de obtenção de informação deste grupo de alimentos foi pergunta dirigida para o número de vezes em que o entrevistado consumia aquele alimento por dia.

3. 0 consumo da terceira categoria de alimentos na qual se incluem embutidos (tais como salsicha, lingüiça, paio, toucinho, salame, e outros) queijo, ovos, banha, gordura hidrogenada, bolacha, sorvete de massa, amendoim, azeitona, salgadinho industrializado e refrigerantes foi investigado sem preocupação com quantificações. Os entrevistados foram inquiridos se tinham 0 costume de consumir esses alimentos, com qual freqüência e se sabiam informar a quantidade comprada no período em que o entrevistado costumava fazer suas compras. Ao contrário das categorias acima, nas quais a freqüência dos alimentos ocorre com certa estabilidade, os dados de consumo destes alimentos são irregulares.

Estas categorias foram assim organizadas pelo grau de dificuldade para quantificar os alimentos consumidos. Esta dificuldade está inversamente relacionada à regularidade e estabilidade com que se apresentam na dieta. Ou seja, da primeira para a terceira categoria aumenta a dificuldade em quantificar os alimentos comprados ou consumidos devido à irregularidade de consumo. Assim sendo, as informações sobre alimentos básicos da dieta foram obtidas através da quantidade comprada; a forma de obtenção de informação sobre alimentos que sofrem maior flutuação de consumo, centrou-se em quantidades e freqüência de alimentos consumidos; e na terceira categoria as questões sobre consumo foram mais abertas.

A história dietética foi incluída no roteiro da entrevista sobre comportamento alimentar e limitou-se à descrição dos alimentos consumidos habitualmente. 0 recordatório alimentar de 24 horas e o questionário de freqüência foram aplicados ao final da entrevista.

RES U LT A D O S

\section{Representações sociais sobre o consumo alimentar e possíveis implicações em inquéritos alimentares}

Ao apresentar como resultado os relatos obtidos na aplicação de um inquérito alimentar 
no contexto de uma entrevista semi estruturada, foi possível reconhecer representações do consumo alimentar.

Os relatos que expressaram flutuações e contradições sobre o consumo alimentar e oscilações nas expressões das práticas alimentares foram agrupados em 5 categorias: informações sobre consumo alimentar relacionadas ao alimento; informações sobre consumo alimentar pelo modo de consumo relacionado ao tipo de alimento; imprecisão nas informações sobre consumo alimentar relacionadas ao entrevistador, e representações sobre consumo alimentar que manifestam frustações e contradições

Nos relatos foram incluídas as falas do pesquisador e de outros participantes ocasionais. 0 " $P$ " identifica o pesquisador, quem realizou a entrevista; 0 " $E$ " identifica o entrevistado, sendo que ao final de cada trecho, entre parênteses, é possível conhecer de qual entrevistado foi recortado o relato; " $T$ " corresponde á existência de uma terceira pessoa que participou da entrevista ou de parte dela e, finalmente a letra "Q" refere-se a uma quarta pessoa presente na entrevista ou em parte dela.

As informações sobre comida nem sempre estão registradas na memória com a mesma exatidão esperada pelo pesquisador, fato este reconhecido por diferentes autores ${ }^{5,8}$. Por outro lado, a alimentação, como instância da vida social e afetiva, faz com que muitas vezes, as informações a seu respeito oscilem entre objetividade e subjetividade, dificultando o discernimento de ambos por parte do especulador. Esta particularidade dos relatos sobre comida pode se exacerbar quando o sujeito da entrevista tem uma pendência com sua alimentação, na medida em que, ao estar submetido a uma prescrição dietética, tenha estabelecido um conflito entre o que come e o que deve comer.

Pôde-se observar que as formas de organização das informações quantitativas foram heterogêneas, tendo em vista que o questionário de freqüência não pré-estabelecia periodicidade, apenas colhia a informação através de critérios definidos pelo próprio entrevistado. Houve entrevistas em que as informações eram bem estruturadas, refletindo uma rotina bem estabelecida de compras e de consumo. Mas, em outros casos, ficava clara a dificuldade do informante responder sobre o seu consumo alimentar e fornecer uma resposta precisa, sugerindo ser esta condição, reflexo da relação do sujeito com o consumo e compras.

A imposição de uma periodicidade por parte do pesquisador delega para o entrevistado os ajustes de sua organização quantitativa e temporal para aquela solicitada. No caso deste estudo, interessava mais conhecer esta organização do entrevistado, porque nosso objetivo foi aproximar-se das representações de suas práticas alimentares. Assim os resultados devem ser lidos também pelo prisma da organização informal do entrevistado. Apesar destas considerações, observou-se em alguns relatos a busca por informações através de perguntas que pré-estabeleciam a variável tempo e quantidade.

Na dinâmica familiar, a presença de comensais que não fazem parte da rotina doméstica traz variações difíceis de serem mensuradas em termos de alimentos consumidos, pela irregularidade com que ocorrem. Veja no exemplo a seguir:

“P: A família é grande, né?

E: A família é e depois, às vezes tem uma e outra, e quando vêm mais pessoas, ....

P: Vem muita gente aqui?

E: Meus parentes mesmo, eu quase não vou, eles vêm, né, minhas irmãs...: Graças a Deus, minhas irmãs vêm, e... vêm com as crianças, né e almoçam, comem bastante, é assim. (E11)".

No Quadro 1 são apresentadas imprecisões das informações sobre consumo alimentar relacionado ao alimento. No relato (E113) observa-se indução do pesquisador em busca de quantidades e, na resposta do entrevistado, a imprecisão so bre as situações em que consome o referido alimento. 
Quadro 1. Imprecisões das informações sobre consumo alimentar relacionadas ao alimento.

Irregularidade da presença do produto

E: Bacon, de vez em quando eu uso.

P: Tá. A senhora compra em pedaço ou fatiado?

E: Em pedaço.

P: Dura quanto tempo um pedaço?

E: Ah!...É irregular. Depende muito da comida, da ocasião (E113).

E: Vou ter que responder pelo último mês, viu! Faz uns 4, 5 meses que eu não compro salsicha. Acho que uns três quilos e meio (E112).

P: E a manteiga, usa de vez em quando? A cada quanto tempo?... Uma vez por mês?

E: Não, não. Não chega a isso não. É quando eu...sabe, tenho aquela vontade de comer manteiga mesmo, então a margarina não vai adiantar. Aí você compra um pacote de manteiga e usa (E113).

\section{Irregularidade das compras}

P: Quantas caixinhas que a senhora gasta por mês de Knorr?

E: Ah, eu compro umas caixinhas de seis. Às vezes eu compro duas, três caixinhas. Eu não faço compra por mês, entende? Quando falta as coisas eu vou comprar (E106).

E: Tem época que eu compro por mês. tem época que eu vou e compro pra quinze dias. Quando muito eu compro por semana (E113).

P: Deixe-me perguntar mais uma coisa, pãozinho a senhora come todo dia?

E: Não, não é todo dia não, é de vez em quando, quando tem dinheiro. Quando tem grana. Quando não tem, faço um bolinho ou uma bolacha salgada (...).

P: 0 feijão a senhora compra ........?

E: Feijão eu compro cinco quilos.

P: Cinco quilos?

E: Quando dá né. Tem mês que dá, tem mês que não dá, aí compro 2 quilos ou 3.

P: E arroz?

E: Arroz eu compro dois pacotes.

P: Dez quilos que você compra?

E: Eu compro 15 quilos de arroz (...).

P: E a carne?

E: Quando tem dinheiro compra, quando não tem, come verdura, come ovos, come uma sardinha em lata, come qualquer coisa (E5).

Quando o questionário de freqüência propõe uma periodicidade está solicitando ao entrevistado que se ajuste a ela. A irregularidade das compras e da presença do produto no cotidiano alimentar não pode se ajustar a uma freqüência sem que se force a um enquadramento de periodicidade regular, que, pode ser artificial. Do mesmo modo que certos alimentos são consumidos sem que haja um registro preciso sobre a quantidade consumida, quer seja pelo tipo de alimento e pela própria forma com que é consumido, conforme se observa no Quadro 2 que apresenta as flutuações das representações sobre consumo alimentar pelo modo de consumo relacionado ao tipo de alimento.

A necessidade de precisar quantidades em inquéritos alimentares e de configurar as refeições para cálculos dietéticos pode levar a definições de consumo de alimentos e quantidades para satisfazer o pesquisador, conforme observado nas representações do consumo alimentar influenciados pelo entrevistador (Quadro 3). Dimensionar 
quantidades de alimentos consumidos é uma prática usual entre o investi-gador que busca precisão e o entrevistado que se esforça em responder a contento (E13 e E12).

A ansiedade por precisão demanda do entrevistado uma posição da qual ele pode não estar seguro. Por exemplo, se um sujeito tem dificuldade em dizer quanto e com que periodicidade consome certo alimento, isto pode refletir o peso que este alimento tem na sua rotina ou a irregularidade com que está sua dieta. Além destes, o valor social atribuído ao alimento ou a suposição de um possível julgamento daquilo que come em vista do que deveria comer, podem determinar as representações de consumo alimentar orientadas por estas tendências.

Quadro 2. Flutuações nas representações sobre consumo alimentar pelo modo de consumo relacionado ao tipo de alimento.

\section{Bebidas}

E: Cafezinho, bebo toda hora.

P: É! E quantas vezes por dia, mais ou menos?

E: Ah, não tenho base (E4).

P: E depois não comeu mais nada? Antes de dormir, nada? Leite?

E: Não, às vezes... ah, ontem.....

T: Guaraná. Você tomou um copo de guaraná.

E: Ontem tomei um copo de guaraná e, eu, às vezes eu,... ontem, eu peguei um pacotinho de bolacha de maizena, né... (E102).

P: E o refrigerante, daria quantos mais ou menos, quantas garrafas por semana mais ou menos? Ou por mês?

E: Você diz pra mim ou para os três?

P: Para os três, para a família.

E: Isso é muito relativo porque nessa época de calor, a pessoa passou na geladeira, toma.

P: Toma. Toma mesmo.

E: Como é que eu vou dizer pra você, sinceramente, eu não tenho controle.

P: Então tá.

E: Eu tomo muito líquido. Eu tomo bastante (E113).

\section{Alimentos}

P: Tá, então a senhora comeu torresminho, e quanto de torresminho?

E: Tomei um, um pouquinho. Veio bastante, porque, eu não contei não, mas foi bastante. Ah, acho que, acho que eu devo ter comido, assim, uns dez torresminhos, tá? (E13).

E: Vou comendo o queijo separado. Eu corto um pedaço e aí vou comendo e eu como com esse pão,... eu corto ele no meio....Então eu passo a manteiga, a manteiga não, a Becel e o queijo. Eu vou comendo e daí eu pego o queijo, um outro queijo e vou tomando o meu café assim... (...).

E: Ah, eu como assim, ó, um pedaço de queijo assim, dois pedaços de queijo assim. Talvez...

P: Dois pedaços assim. E: Talvez até um pouquinho maior, vai. Porque sabe, é difícil, é difícil te falar, porque eu vou, eu vou cortando.

R: Você já vai pegando os pedaços...

E: Eu não ponho, eu vou cortando e vou comendo (E105).

P: E aí, mais tarde a senhora comeu o que? Só isso?

E: Comi uma bolacha

P: E que bolacha que foi?

E: Ah uma...

T: Sequilhinho.

P: Ah sequilhinho. Quantos a senhora comeu, a senhora tem idéia?

E: Ah umas 4, 5, $6 \ldots$ (E7). 
Quadro 3. Representações sobre consumo alimentar influenciados pelo entrevistador.

\section{Indução das respostas pela busca de informações precisas}

P: E o senhor chega a comer o quê, um pacotinho (salgadinho industrializado) desse por semana...

E: Não, só um pouquinho cada vez assim.

P: Toda semana o senhor come um pouquinho.

E: Às vezes eu como.

P: Tá, que tamanho? Esse pacotinho aqui? Ou desse grande aqui?

E: É assim ,mais ou menos.

P: Qual desse aqui o senhor come?

E: Desse assim pode ser, que a gente come (E6).

P: E refrigerante, vocês costumam tomar todo dia ? Normalmente, você toma o quê, uns dois copos, três...?

E: Ah, por aí (E102).

E: Do dia a dia em casa? A comida do dia a dia em casa é...

P: Arroz, feijão...

E: Tem arroz, feijão, carne, isso é...

P: Salada sempre?

E: Salada, sempre salada. Em casa sempre teve salada. Não é sempre, mas sempre tem uma verdura cozida além da salada, tirando a salada (E105).

$P$ : E, e margarina, passa quanto?

E: Mais ou menos umas 50 gramas (E13).

E: Eu não tenho base, assim do conteúdo. Mas eu acho que eu uso uns, acho que eu uso mais de um, de um quilo de banha, assim por mês e derretidinha. Acho que eu uso mais (E12).

O uso de noções como "pouco" e "muito" dependem de valores de referência do entrevistado. 0 que é muito para uma pessoa pode ser pouco para outra. Com muita freqüência eles referiam usar pouco sal. Todavia, as informações obtidas sobre disponibilidade deste alimento indicam o contrário.

A memória do entrevistado e as contradições observadas numa mesma entrevista mostram que se 0 entrevistador se detiver nas informações emitidas durante o preenchimento dos protocolos do inquérito alimentar, as contradições podem ficar ocultas, o que não significa maior precisão dos dados colhidos como registrado nos relatos do Quadro 4, que traz representações sobre o consumo alimentar que manifestam flutuações e contradições. Do diálogo proporcionado pela entrevista semi-estruturada sem ter sido explicitado tratar-se de um estudo sobre alimentação e nutrição, emergiram informações que podem ser entendidas como incoerentes, no entanto, visto de uma outra ótica, estas flutuações são peculiares às repre-sentações sociais nas quais elementos ressaltados podem derivar de uma dada circunstância.

A presença de uma terceira pessoa pode contribuir nos inquéritos alimentares, pois funciona como mediador e por não ser o sujeito da entrevista, apresenta outros fatos de consumo, conforme se observa nos relatos abaixo:

"P: E doce?

$\mathrm{E}: \mathrm{Ah}$, doce a gente come mais.

P: Todo dia?

E: Não, todo dia também não, mas sempre compra aquelas bolachas.

T: Não todo dia, mas quase toda hora (E7).

Q: Você não tomou nada lá?

E: Não.

$\mathrm{T}$ : E aquela água de coco, quem tomou?

E: Não, é verdade. Bom, depois eu tomei uma água de coco (E104). 
Quadro 4. Representações sobre consumo alimentar que manifestam flutuações e contradições.

\section{Falta de memória do entrevistado}

E: No jantar o que que eu comi? Na janta muitas vezes eu não... Deixa eu ver se eu lembro. Eu sei que acho que foi melancia, fiquei se, se... Eu fui, eu fui pra casa era tarde. Bom, ontem eu não jantei (E110).

P: Tá, e o que o senhor almoçou ontem?

E: Ontem foi... foi bife, né? Foi sim.

T: Sabe que eu não me lembro o que eu fiz ontem, de almoço.

E: Foi bife sim.

T: Não foi carne moída não?

E: Ah, foi carne moída!

P: Carne moída. E arroz comeu?

E: Arroz comi.

T: Arroz, feijão e carne moída (E6).

E: E meio-dia eu almocei. 0 que que eu almocei? Deixa eu ver. Sabe que eu não lembro mais. Hum, mas eu sou esquecida, meu Deus do céu. 0 que foi que eu fiz pro almoço ontem? Arroz, feijão sempre teve. E só. Arroz, feijão, bata..., é, bife e salada de acelga. P: Batata não?

E: Batata não (E106).

P: Ontem você tomou ou não tomou lanche da tarde? Você não comeu nada à tarde?

E: Não.

P: Nem beliscou nada?

E: Ontem à tarde não. Comi sim, comi um pão de batata, porque a gente acabou indo para o clube, e aí acabei comendo um pão de batata.

P: Um pão de batata. Tá. Com? Pra beber, nada?

E: Cerveja (E108).

\section{Contradição observada no decorrer de uma mesma entrevista}

P: Não come mais pão?

E: Não como mais. (em outro trecho da entrevista)

$P$ : Mas você come também um pãozinho, né?

E: Nossa Senhora se como! Eu adoro comer pão (E106).

E: Aí depois de noite teve o bolo, né? Teve o bolo de chocolate, teve bolo de fubá mas eu não como porque faz mal. Teve bolo de, de coco com leite condensado. Bem feitinho e chá mate. Mas eu não tomei chá mate nem comi bolo.

P: A senhora não comeu nada de doce?

E: Peguei um pedacinho assim do bolo de, de coco... (E12).

P: Certo, 6 refrigerantes de 2 litros. Então você compra 2 pacotes de ...

E: Dois pacotes de diet e 2 pacotes do outro.

P: Do outro é o quê?

E: É Sprit, Guaraná. Coca eu não gosto que as crianças tomem. Agora refrigerante aqui é só sábado e domingo. Agora você me pergunte quanto que eu gasto de suco de laranja? Eu gasto 30 quilos por semana de laranja.

P: Nossa, bastante.

E: Compro aquele saco grande, no Macro, toda semana e uso isso na semana inteira. Então quando a laranja vem doce, é o próprio açúcar da laranja que eles usam, e quando vem azeda, porque tem umas que vem triste, eles adoçam, mas eu não adoço nada. Agora eu não gosto de comer bebendo líquido, eu me sinto estufada. Ou eu tomo antes de comer, quando eu faço já tomo, ou então só vou tomar assim bem depois que eu almocei, de tardezinha que aí eu encho uma caneca e tomo (...).

P: E suco?

E: Nem sempre. Por semana, eu compro assim, o diet do meu marido, umas 2 caixas diet e umas $2 \ldots$ porque são 12 refrigerantes de 2 litros, né (E111).

T: Refrigerante é só mesmo final de semana. E mesmo para os meninos, quando eles eram adolescentes, não tinha esse negócio, sabe, de ficar só sanduíche, só refrigerante (...).

T: A noite, só a base de lanche. Mas a gente faz por exemplo, o nosso lanche é uma salada com atum, tá, e tomate, alface, ovos cozidos ou é um cachorro quente ou sempre tem alguma coisa a mais nesse lanche ou é um patê de atum, sabe que a gente faz... (...).

E: Agora, tem por exemplo, quando tá muito quente esses, esses dias aí a gente toma refrigerante Diet (E105). 
Em outro relato a situação se repete:

P: E margarina?

T: Usa bastante.

P: Quantos potes de margarina vocês compram? Compram de meio quilo ou compram do pote menor?

E: Acho que é de 500 gramas.

Q: De meio quilo.

P: Quantos potes mais ou menos?

Q: Dois.

T: 0 que?

Q: Margarina.

E: Você compra Becel, não compra?

T: Compra duas Becel.

Q: Pequena.

T: Pequena. E duas da margarina light.

E: Quatro, mas isso não vai dar.

P: Duas de meio quilo?

Q: É.

T: Duas de meio quilo e duas de 250 (E104).

E: Às vezes assim, a gente pega um pedacinho de salaminho e come, né.

P: Ontem o senhor comeu?

E: Ontem eu comi. Quase todo dia, né.

P: Quase todo dia?

T: Volta e meia ele tá lá no salaminho! (E6)".

Não se pode atribuir às condições socioeconômicas e culturais o caráter flexível das expressões sobre consumo alimentar, pois os discursos dos sujeitos dos dois grupos apresentaram as mesmas características, o que reforça a premissa de que o objeto - práticas alimentares - não é captado em suas manifestações concreta e precisa como seria desejável. Isto não é o mesmo que dizer que variáveis como sexo, religião, condições socioeconômicas e culturais, histórico pessoal, entre outras não afetem a visão de mundo. 0 que se afirma aqui é que, o objeto dos inquéritos alimentares, as práticas alimentares, se manifestam como representações cuja estrutura oscilante, muitas vezes é negligenciada na interpretação de seus resultados.

0 conjunto de dificuldades aqui apresentados pode estar presente nos inquéritos alimentares, no entanto, como a metodologia busca precisão, estes elementos são convertidos em dados objetivos. Pode-se supor que tais dificuldades estariam acentuadas se 0 entrevistado estivesse submetido a algum tipo de restrição alimentar que o levasse a manter uma censura sobre suas informações de consumo. No entanto, esta flexibilidade e imprecisão podem ser explicadas pelo fato da alimentação ser uma prática complexa expressa como representações do consumo alimentar. Tais colocações não invalidam os métodos, mas indicam que eles abordam as representações do consumo alimentar.

D I S C U S S Ã O

Discutir as flutuações e contradições nas manifestações sobre consumo alimentar como representações sociais muda a perspectiva de análise das categorias aqui apresentadas. Representação social é uma construção mental da realidade que possibilita a compreensão e organização do mundo, bem como orienta 0 comportamento ${ }^{2,3}$.

0 complexo de elementos constituintes das representações sobre alimentação não é regido, necessariamente, pela coerência, ou melhor, ela existe circunstancialmente, imposta por uma dada situação ${ }^{19}$. Exemplifica 0 autor que um mesmo entrevistado, quando referia-se a comida de sua casa, a colocava como sendo a melhor e a preferida e, ao falar de sua experiência com as refeições feitas fora de casa, o entrevistado dizia que comia melhor fora de casa. Suas conclusões sobre a dinâmica das representações sobre a comida apontam os elementos constituintes, convivendo em estruturas flexíveis, adaptando-se às circunstâncias, ao gosto, aos valores, entre outros. Como as representações sociais situam-se entre o discurso e a prática, podem ser mais flexíveis no discurso do que no plano da experiência.

Na proposição de Carrasco i Pons ${ }^{14}$ sobre a existência de uma distância entre a visão que os indivíduos manifestam de suas práticas e as práticas propriamente ditas, pode-se entender tais representações localizadas no contexto entre 0 
que se come e o que se deve comer uma vez que os sujeitos entrevistados estavam submetidos à prescrição dietética.

Cassidy ${ }^{6}$ recomenda a combinação de métodos quantitativos e qualitativos para melhor aprimorar instrumentos culturalmente sensíveis, capazes de apreender a realidade sóciocultural da população estudada.

A pesquisa culturalmente sensível proposta por Cassidy ${ }^{6}$ requer que o pesquisador perceba que a precisão dos dados é uma função do quanto conhecem as pessoas que eles querem entender e até onde os entrevistados confiam nele. As ações e concepções de ambos, pesquisador e entrevistado, são culturalmente carregadas, o que afeta o modo com que as pessoas entendem a realidade, o significado que impõem às palavras e atos e quais valores dão a conceitos tais como saúde e boa alimentação. A consciência de seus próprios sistemas de valores e pressuposições permitirá ao pesquisador conseguir melhor acuidade de seus resultados e possibilitará o discernimento de dados precisos e dados interpretáveis.

\section{O N C L U SÃ O}

A estratégia metodológica utilizada permitiu constatar que a metodologia qualitativa pode contribuir com propriedade para mapear representação do consumo e das práticas alimentares. Focalizar as imprecisões e flutuações dos inquéritos alimentares como representações não esvazia o valor e a importância do mesmo, mas possibilita uma proximidade com o objeto de estudo, sentido essencial da busca de informações sobre consumo. A alimentação não parece ser uma prática cuja abordagem por inquéritos alimentares dê a ela a precisão almejada por estudos de consumo alimentar, sobretudo em sujeitos submetidos a tratamento dietético.

\section{REFERÊ N CIAS}

1. Garcia RWD. Representações sociais da alimentação e saúde e suas repercussões no comportamento alimentar. Physis- Rev Saúde Coletiva 1997; 7(2):51-68.

2. Moscovici S. Representação Social da Psicanálise. Rio de Janeiro: Zahar; 1978.

3. Jodelet D. La representación social: fenomenos, concepto y teoria. In: Psicologia social II. 2.ed. Barcelona: Paidós; 1998. p.469-94.

4. Keane A, Willetts A. Concepts of healthy eating: an anthropological investigation in South East London. London: Goldsmiths University of London; 1996. $66 p$.

5. Witschi JC. Short-term dietary recall and recording methods. In: Willett W. Nutritional epidemiology. New York: Oxford University Press; 1990. p.52-68.

6. Cassidy C. Walk a mile in my shoes: culturaly sensitive food habits research. Am J Clin Nutr 1994; 59:190S-7S.

7. James WPT, Bingham SA, Cole TJ. Epidemiological assessment of dietary intake. Nutr Cancer 1981; 2(4):203-12.

8. Bingham SA, Cummings JH. Urine nitrogen as an independent validatory measure of dietary intake: a study of nitrogen balance in individuals consuming their normal diet. Am J Clin Nutr 1985; 42:1276-89.

9. Sabaté J. Estimación de la ingesta dietética: métodos y desafíos. Med Clín, 1993; 100:591-6.

10. Brussaard JH, Lowik MR, Steingrimsdottir L, Moller A, Kearney J, De Henauw $S$, et al. For EFCOSUM Group. A European food consumption survey method-conclusions and recommendations. Eur J Clin Nutr 2002; 56(Suppl 2):S89-94.

11. Steingrimsdottir L, Ovesen L, M oreiras $\mathrm{O}$, Jacob $\mathrm{S}$. For EFCOSUM Group. Selection of relevant dietary indicators for health. Eur] Clin Nutr 2002; 56(Suppl 2):S8-11.

12. Bratteby LE, Sandhagen B, Fan H, Enghard H, Samuelson $G$. Total energy expenditure and physical activity as assessed by the doubly labeled water method in Swedish adolescents in whom energy intake was understimated by 7 day diet records. Am J Clin Nutr 1998; 67:905-11. 
13. Black AE. Metodos de valoración dietética: errores e incertidumbres. Anais do II Congresso Mundial Vasco - Problemas de la nutrición en las sociedades desarroladas, Barcelona: Salvat; 1988. p.25-33.

14. Carrasco S i Pons. Antropologia i alimentació Una proposta per l'estudi de la cultura alimentària. Bellaterra: Servei de Publicacións de la Universitat Autònoma de Barcelona; 1992. 124p.

15. Juliano D. Aculturación. In: Aguirre-Baztán A, editor. Diccionário temático de antropología. 2.ed. Barcelona: Editorial Boixareu Universitária, 1993. p.1-15.
16. Gibson RS. Principles of nutritional assessment. New York: Oxford University Press, 1990. p.85-96

17. Queiroz MIP. Relatos orais: do "indizível" ao "dizível". Ciência e Cultura 1987; 39(3):272-86.

18. Zabotto CB, Viana RPT, GIL M F. Registro fotográfico para inquéritos dietéticos: utensílios e porções. Campinas: Unicamp; 1996. 74p.

19. Garcia RWD. Práticas e comportamento alimentar no meio urbano: um estudo no centro da cidade de São Paulo. Cad Saúde Pública 1997; 13(2): 455-67.

Recebido para publicação em 11 de março de 2002 e aceito em 28 de maio de 2003. 